\title{
SEASONAL VARIATION OF HEAVY METALS IN WATER SAMPLES FROM THE SITALAKHYA RIVER
}

\author{
MUHAMMAD ZAKARUL ISLAM*', MOHAMMAD ALAUL AZIM, RAFIQUL \\ ISLAM \\ Department of Applied Chemistry and Chemical Technology, University of Dhaka, \\ Dhaka-1000, Bangladesh
}

AND

SHAMSHED B. QURAISHI

Chemistry Division, Atomic Energy Centre, Dhaka, Bangladesh

\begin{abstract}
The study was carried out to analyze the concentration of the trace heavy elements in water from five different stations of Sitalakhya river and was sampled every three months from December 4 to September 5. All the samples were analyzed for the determination of trace elements by using Atomic Absorption Spectrophotometry method. The concentration of iron, lead, cadmium, manganese, cobalt, nickel, chromium, zinc, copper ranged from 1.26 - 8.31, <17.96 - 22.60, <3.00 3.72, 29.38 - 197.33, <4.05 - 7.91, <10.66 - 23.84, <4.05 - 9.57, 7.86 - 36.11 and 3.08 - $12.82 \mu \mathrm{g} / \mathrm{l}$. The concentration of different elements varied in different season and the maximum amount was observed in the dry season (March). The present study also revealed that although the pollution level is not alarming yet but it increasing slowly. The water quality characteristics were within the permissible level of Bangladesh standard and below the EPA and WHO standard except for iron. From this study it is clear that the water of this river is not an immediate threat to ecosystem but some parameters may gradually deteriorate with time and in future may cause a threat to ecosystem.
\end{abstract}

\section{INTRODUCTION}

Heavy metal contamination in water is an increasing worldwide environmental concern. $^{(1)}$ Water has been used much as a recipient of toxic and solid waste from domestic, industrial and agricultural run off. Waterborne chemical pollution entering rivers and streams cause tremendous amounts of destruction. There are many chemical industries in and around Dhaka city and Narayanganj town. Most of our industries discharge their effluents into water body like rivers without any treatment, which contaminate surface water. At present the underground water is not safe for drinking purpose because of arsenic contamination. So the scarcity of potable water can be solved by using rainwater and surface water. But we get the rain water for two or three months in a year. So the use of surface water like from river water for drinking purposes is the

*Author for correspondence Email: write_zakarul@yahoo.com. 
immediate solution and for that reason, the present status of river water quality is very important for the design of proper treatment. The aims of this work are: (1) Monitoring seasonal variations of trace elements in the Sitalakhya river; (2) Finding the environmental impact of industrial effluents on water bodies; (3) Providing the base line data on surface water quality to policy makers to manage and protect water bodies from water pollution for maintaining environmental ecological balance.

\section{EXPERIMENTAL}

Samples were collected every three months from five sites in the Sitalakhya river from December 1904 to September 1905. Different types of sites were chosen to investigate spatial variability of different elements in different sites. The sampling locations are shown in Fig. 1.

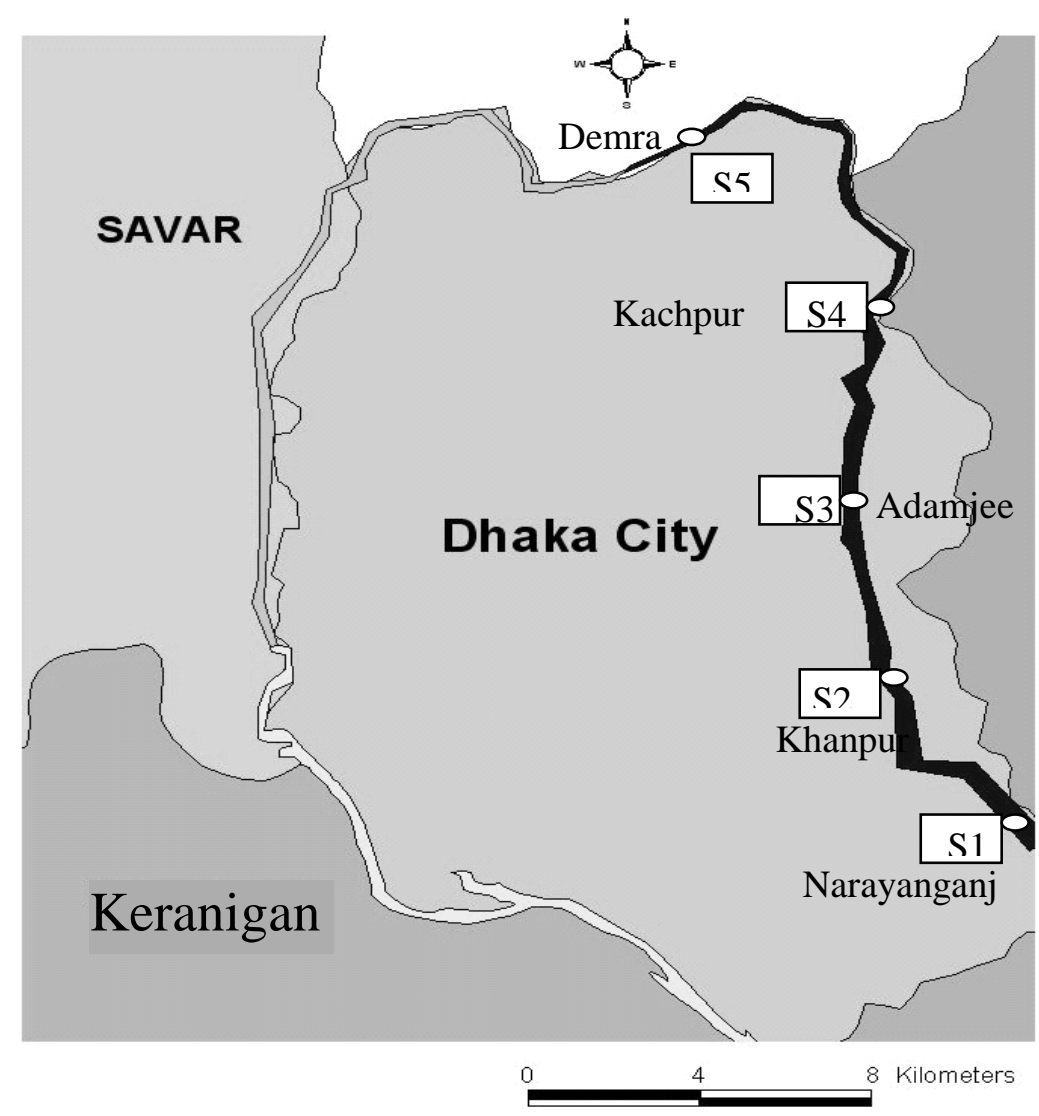

Fig. 1. Sampling locations of Sitalakhya river.

Selection of locations : The significance of a chemical analysis depends to a large extent on the sites of sample collection. An ideal sample should be one which is both 
valid and representative. These conditions are met by collection of samples through a process of appropriate location selection. This ensures that the composition of sample is identical to that of the water body from which it is collected and sample shares the same physico-chemical characteristic with the sampled water at the time and site of sampling. The locations of sampling of surface water of the Sitalakhya river were selected on the basis of (1) Sites of industrial complexes, mainly chemical industries along the stretch of the two rivers; (2) Sites of the rivers where drainage effluents like domestic, municipal and hospital wastes were discharged.

Description of sampling locations: The Narayanganj site is situated by the side of main Narayanganj city. Municipal and industrial sewerage are directly dumped into this site. In the Khanpur location only some sand loaded tracks are loaded and unloaded there. The municipal sewerage is also discharged there. The side of former Adamjee Jute Mills Ltd. locates the Adamjee location. Now an EPZ is being constructed in this location. Different ships are repaired there and the liquid effluents of some dyeing textiles industries are mixed with the river water without any treatment. The Kanchpur location is located besides the Kanchpur bridge which connects the busiest road of Chitagong and Dhaka city . The ship breaking machines and the effluents from the Sinha Textile Ltd. are discharged into the upstream of this location. The Demra location is named as the Demra ghat. From that location Sitalakhya river is separated into two mainstreams: Sitalakhya river and Balu river. It is always crowded by sand loading steamers and transport boats.

Collection of samples and analysis: Samples of surface water were collected by dipping two, one liter capacity white polyethylene plastic bottles. The bottles were previously washed thoroughly with detergents and deionized water and then soaked by filling with $20 \%$ dil. $\mathrm{HNO}_{3}$ for 24 hours. The bottles were then washed thoroughly with tap water and then with distilled deionized water. During collection of samples, bottles were rinsed properly with the river water samples. The collected samples were carried to the laboratory as quickly as possible. After bringing to the lab. the samples were acidified with concentrated $\mathrm{HNO}_{3}$ to get $\mathrm{pH}<2.0$ and kept in the refrigerator at $4^{0} \mathrm{C}$ for further analysis. The trace elements were determined by atomic absorption spectrophotometric method.

\section{RESULTS AND DISCUSSION}

Iron: The concentration of iron was found remarkably higher than other metals at all the locations of Sitalakhya. The maximum and minimum concentrations of iron were $8.31 \mathrm{mg} / \mathrm{L}$ (June) at Khanpur and $1.26 \mathrm{mg} / \mathrm{l}$ (December) at Demra (Fig. 2) throughout the study period. The present findings are higher than that observed for Po river (Italy) ${ }^{(2)}$, Tuoto river (China) $)^{(3)}$, Mississippi river (USA) ${ }^{(4)}$ and the Indus river. (Pakistan). ${ }^{(5)}$ The values were $0.001-0.011,5.23,0.135$ and $0.012-1.54 \mathrm{mg} / \mathrm{L}$, respectively. The discharge 


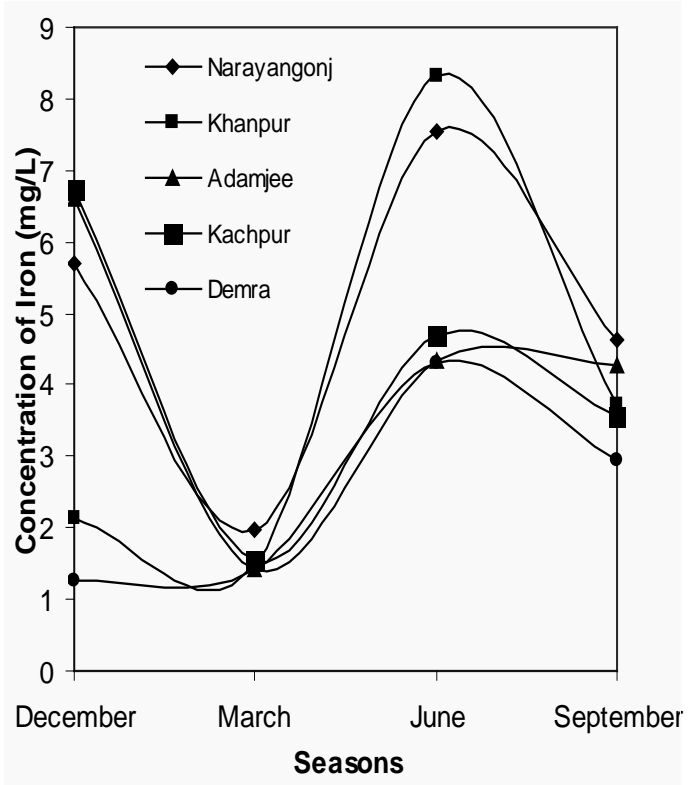

Fig. 2. Seasonal variation of iron (mg/l) in water samples at different locations of the Sitalakhya river

of various types of waste materials from textiles, leather tanning, chemical industries etc. into the river water accelerate the concentration of iron. High level of iron in water can be a problem for poultry due to its staining characteristics; even $3.00 \mathrm{mg} / \mathrm{L}$ can be objectionable. Concentration of iron in the river exceeded the permissible level of iron in river water which is set at $0.30 \mathrm{mg} / \mathrm{L}$. So pre-treatment is necessary before using this water for drinking purposes.

Lead: The concentration of lead ranged from $<17.96-22.60 \mu \mathrm{g} / \mathrm{L}$ through out the study period. The highest concentration was found at Adamjee, Narayanganj and Kanchpur (22.60 $\mu \mathrm{g} / \mathrm{L}$, March). In the months of June and September it was always less than detection limit $17.96 \mu \mathrm{g} / \mathrm{L}$ of the AAS (Table 1). Present findings are higher than the findings of Pettine ${ }^{2}$. But in most of the samples the concentration of lead was less than detection limit. The level of lead is still much below than the permissible levels of WHO and USPH standard. In this respect the lead content in the Sitalakhya river is not in danger for human health and for aquatic life.

Table 1

Concentration of toxic metals in the sitalakhya river water at different sampling sites in different month of the year

\begin{tabular}{|c|c|c|c|c|c|}
\hline \multirow{2}{*}{$\begin{array}{l}\text { Trace } \\
\text { elements }\end{array}$} & \multirow[t]{2}{*}{ Location } & \multicolumn{4}{|c|}{ Season } \\
\hline & & December & March & June & September \\
\hline \multirow[t]{2}{*}{ Lead } & Narayanganj & 20.27 & 22.60 & $<17.96(\mathrm{DL})$ & $<17.96$ (DL) \\
\hline & Khanpur & 20.27 & $<17.96$ (DL) & $<17.96(\mathrm{DL})$ & $<17.96(\mathrm{DL})$ \\
\hline
\end{tabular}




\begin{tabular}{llllll} 
& Adamjee & 20.27 & 22.60 & $<17.96(\mathrm{DL})$ & $<17.96(\mathrm{DL})$ \\
& Kanchpur & 20.27 & 22.60 & $<17.96(\mathrm{DL})$ & $<17.96(\mathrm{DL})$ \\
& Demra & $<17.96(\mathrm{DL})$ & $<17.96(\mathrm{DL})$ & $<17.96(\mathrm{DL})$ & $<17.96(\mathrm{DL})$ \\
Cadmium & Narayanganj & $<3.00(\mathrm{DL})$ & $<3.00(\mathrm{DL})$ & $<3.00(\mathrm{DL})$ & $<3.00(\mathrm{DL})$ \\
& Khanpur & $<3.00(\mathrm{DL})$ & 3.17 & $<3.00(\mathrm{DL})$ & $<3.00(\mathrm{DL})$ \\
& Adamjee & $<3.00(\mathrm{DL})$ & $<3.00(\mathrm{DL})$ & $<3.00(\mathrm{DL})$ & $<3.00(\mathrm{DL})$ \\
& Kanchpur & $<3.00(\mathrm{DL})$ & $<3.00(\mathrm{DL})$ & $<3.00(\mathrm{DL})$ & $<3.00(\mathrm{DL})$ \\
& Demra & $<3.00(\mathrm{DL})$ & 3.72 & $<3.00(\mathrm{DL})$ & $<3.00(\mathrm{DL})$ \\
& Narayanganj & $<4.05(\mathrm{DL})$ & $<4.05(\mathrm{DL})$ & $<4.05(\mathrm{DL})$ & $<4.05(\mathrm{DL})$ \\
& Khanpur & $<4.05(\mathrm{DL})$ & $<4.05(\mathrm{DL})$ & 7.91 & $<4.05(\mathrm{DL})$ \\
& Adamjee & $<4.05(\mathrm{DL})$ & $<4.05(\mathrm{DL})$ & $<4.05(\mathrm{DL})$ & $<4.05(\mathrm{DL})$ \\
& Kanchpur & $<4.05(\mathrm{DL})$ & $<4.05(\mathrm{DL})$ & $<4.05(\mathrm{DL})$ & $<4.05(\mathrm{DL})$ \\
& Demra & $<4.05(\mathrm{DL})$ & $<4.05(\mathrm{DL})$ & 6.32 & $<4.05(\mathrm{DL})$ \\
& Narayanganj & $<10.66(\mathrm{DL})$ & $<10.66(\mathrm{DL})$ & $<10.66(\mathrm{DL})$ & $<10.66(\mathrm{DL})$ \\
& Khanpur & $<10.66(\mathrm{DL})$ & $<10.66(\mathrm{DL})$ & 23.84 & $<10.66(\mathrm{DL})$ \\
& Adamjee & $<10.66(\mathrm{DL})$ & $<10.66(\mathrm{DL})$ & $<10.66(\mathrm{DL})$ & $<10.66(\mathrm{DL})$ \\
& Kanchpur & $<10.66(\mathrm{DL})$ & $<10.66(\mathrm{DL})$ & $12.71(\mathrm{DL})$ & $<10.66(\mathrm{DL})$ \\
& Demra & $<10.66(\mathrm{DL})$ & $<10.66(\mathrm{DL})$ & $15.10(\mathrm{DL})$ & $<10.66(\mathrm{DL})$ \\
& Narayanganj & $<4.05(\mathrm{DL})$ & 9.25 & $<4.05(\mathrm{DL})$ & $<4.05(\mathrm{DL})$ \\
& Khanpur & $<4.05(\mathrm{DL})$ & $<4.05(\mathrm{DL})$ & $<4.05(\mathrm{DL})$ & $<4.05(\mathrm{DL})$ \\
& Adamjee & $<4.05(\mathrm{DL})$ & $<4.05(\mathrm{DL})$ & $<4.05(\mathrm{DL})$ & $<4.05(\mathrm{DL})$ \\
& Kanchpur & 9.57 & $<4.05(\mathrm{DL})$ & $<4.05(\mathrm{DL})$ & $<4.05(\mathrm{DL})$ \\
& Demra & $<4.05(\mathrm{DL})$ & $<4.05(\mathrm{DL})$ & $<4.05(\mathrm{DL})$ & $<4.05(\mathrm{DL})$ \\
\hline
\end{tabular}

Cadmium: It is clearly observed from Table 1 that the concentration of cadmium was always less than the detection limit of $3.00 \mu \mathrm{g} / \mathrm{L}$ in all the locations except for Demra (3.72 $\mu \mathrm{g} / \mathrm{L})$ and Khanpur $(3.17 \mu \mathrm{g} / \mathrm{L})$ in the month of March. In the Mississippi river (USA) $^{(4)}$, The indus river (Pakistan) $)^{(5)}$ the cadmium concentration was found higher than the present study value. Pettine ${ }^{(2)}$ worked on dissolved particulate cadmium and observed low seasonal variation. The maximum permissible concentration of cadmium for drinking water is $10 \mu \mathrm{g} / \mathrm{L}$. The present data show that these are lower than the permissible limit. It indicates that the quality of surface water of Sitalakhya river is not alarming in terms of cadmium pollution.

Cobalt: The concentration of cobalt was always less than $4.05 \mu \mathrm{g} / \mathrm{L}$ for all the locations throughout the study period except for the Khanpur which was $7.91 \mu \mathrm{g} / \mathrm{L}$ in the month of June and $6.32 \mu \mathrm{g} / \mathrm{L}$ at Demra in the same month (Table 1). Boyd and others studied cobalt content in the Mississippi river $^{(4)}$ water, U.S.A and found the concentration of cobalt is $5.27 \mu \mathrm{g} / \mathrm{L}$. The present values (Table 1) are lower than the standard limit. So the concentrations of cobalt are not harmful for aquatic biota as well as for human consumption. 
Manganese: It is seen in the Fig. 3 that the maximum concentration of manganese was found in December at all the locations except of Demra and the maximum value was $197.33 \mu \mathrm{g} / \mathrm{L}$ at Kanchpur. The minimum level was found during September at all the

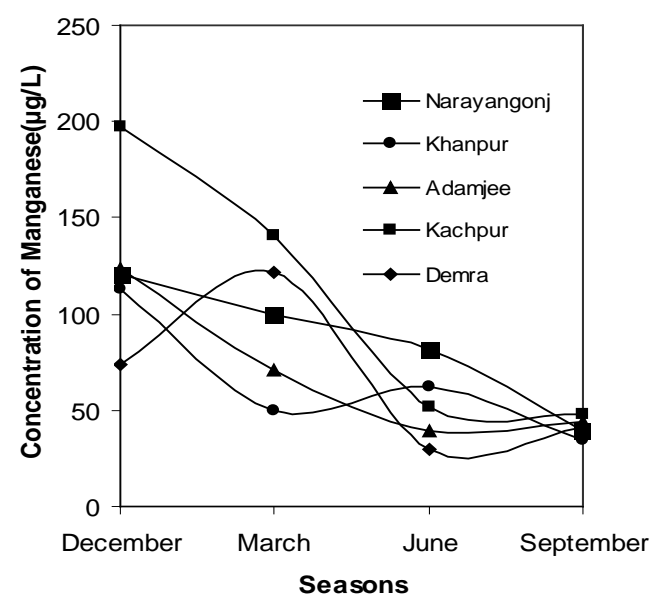


Fig. 3. Seasonal variation of manganese $(\mu \mathrm{g} / \mathrm{L})$ in water samples at different locations of the Sitalakhya river.

locations but the lowest amount of manganese was found at Demra in June, $(29.38 \mu \mathrm{g} / \mathrm{L})$. Only in Tuoto river (Italy) ${ }^{(3)}$, manganese concentration is higher than the Sitalakhya river's present manganese content. The maximum concentration of manganese in the water of the Po river ${ }^{(2)}$ in Italy at spring season was $17.60 \mu \mathrm{g} / \mathrm{L}$ which was much lower than the present study. The maximum permissible USPH standard of manganese for drinking water purposes is set at $50 \mu \mathrm{g} / \mathrm{L}$. The concentrations of manganese in the river water are higher than that of the standard limit of drinking water supply.

Nickel: Only during June the concentration of nickel was higher than $10.66 \mu \mathrm{g} / \mathrm{L}$ in three points, which were Kanchpur, Khanpur and Demra. Among these points the highest concentration was $23.84 \mu \mathrm{g} / \mathrm{L}$ in the location of Khanpur in June (Table 1). Pettine worked on nickel in the water samples of river Po, Italy and found the concentration of nickel within the range $0.44-4.32 \mu \mathrm{g} / \mathrm{L}$. The concentrations of nickel in the surface water of the Sitalakhya river were in the range of $<10.66-23.84 \mu \mathrm{g} / \mathrm{L}$. The present investigation exceed the findings of Pettine ${ }^{(2)}$. The concentrations of nickel observed in the present study are not above the permissible limit of USPH $50 \mu \mathrm{g} / \mathrm{L}$ for domestic water. So, it is not harmful for aquatic biota of Sitalakhya river as well as for human consumption.

Table 3

Trace elements of some drinking water standards

\begin{tabular}{lcccc}
\hline \multicolumn{1}{c}{$\begin{array}{c}\text { Parameters } \\
\mu \mathrm{g} / \mathrm{L}\end{array}$} & $\begin{array}{c}\text { WHO } \\
\text { standard }\end{array}$ & $\begin{array}{c}\text { EPA } \\
\text { standard }\end{array}$ & $\begin{array}{c}\text { Bangladesh } \\
\text { standard }\end{array}$ & $\begin{array}{c}\text { USPHS standard for } \\
\text { domestic water supply }\end{array}$ \\
\hline Lead & 50 & 15 & 50 & 50 \\
Cadmium & 10 & 5 & 5 & 10 \\
Iron & 0.3 & 0.3 & 0.3 & $<0.30$ \\
Zinc & - & 5000 & 5000 & 5000 \\
Copper & 1500 & 1300 & 1000 & 1000 \\
Chromium & 50 & 10 & 50 & 50 \\
Manganese & 50 & 50 & 100 & 100 \\
Cobalt & - & - & - & - \\
Nickel & - & 100 & 100 & 100 \\
\hline
\end{tabular}


Chromium: The concentration of chromium was only detected in Kanchpur and Narayanganj location in December $(9.57 \mu \mathrm{g} / \mathrm{L})$ and March $(9.25 \mu \mathrm{g} / \mathrm{L})$, respectively. Besides these, all points had concentration less than $4.05 \mu \mathrm{g} / \mathrm{L}$ throughout the study period (Table 1). Zhang et al. (1992) ${ }^{(3)}$ studied the contents of chromium in the Tuoto and the Beilu rivers and found its concentration 21.00 and $93.36 \mu \mathrm{g} / \mathrm{l}$, respectively. The concentrations of chromium over maximum period of time were less than the detection limit in the Sitalakhya river.

Zinc: In December, March, June maximum concentration of zinc was found 22.53 $\mu \mathrm{g} / \mathrm{L}, 24.68 \mu \mathrm{g} / \mathrm{L}, 14.86 \mu \mathrm{g} / \mathrm{L})$ in Narayangonj location, but in September that was at Demra $(36.11 \mu \mathrm{g} / \mathrm{L})$. In September the variation of concentration of zinc in different

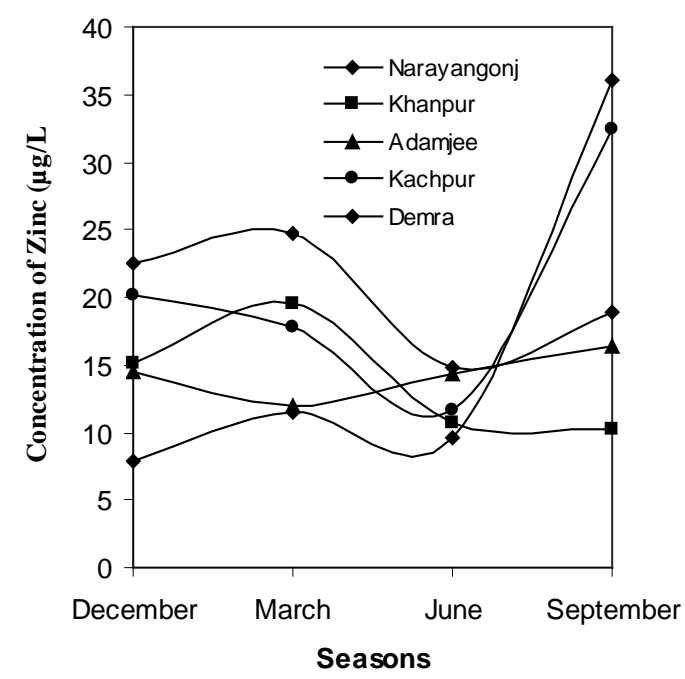

Fig. 4. Seasonal variation of Zinc $(\mu \mathrm{g} / \mathrm{L})$ in water samples at different locations of the Sitalakhya river.

locations is higher (Fig. 4.) The maximum and minimum concentration of zinc was 36.11 $\mu \mathrm{g} / \mathrm{L}$ (September), $7.86 \mu \mathrm{g} / \mathrm{L}$ (December) found at Demra. Jeniffer, Bubb worked on the water samples of the Stour river ${ }^{(6)}$, U.K. and found the concentration of zinc within the range 10-325 $\mu \mathrm{g} / \mathrm{L}$. The USPH and WHO standards of zinc for drinking water are 5,000 and $5000 \mu \mathrm{g} / \mathrm{L}$. Our observed values are within these limits.

Copper: In the months of December, March and June the maximum concentration of copper was found $10.26 \mu \mathrm{g} / \mathrm{L}$ (Kanchpur), $9.99 \mu \mathrm{g} / \mathrm{L}$ (Narayanganj) and $12.82 \mu \mathrm{g} / \mathrm{L}$ (Kanchpur). The maximum and minimum concentration of copper was $12.82 \mu \mathrm{g} / \mathrm{L}$ (June) and $3.08 \mu \mathrm{g} / \mathrm{L}$ (December) found at Kanchpur and Demra (Fig. 5) respectively. The present findings show much lower values than the concentrations of copper in the Indus river $^{(5)}$, Pakistan and Mississippi river ${ }^{(4)}$, USA. The maximum permissible concentration of copper for aquatic life and fish is $500 \mu \mathrm{g} / \mathrm{l}$. The recommended maximum concentration 
of copper for drinking water supply with respect to USPH and WHO standard is 1000 and $1500 \mu \mathrm{g} / \mathrm{L}$, respectively. The observed values are below the permissible level.

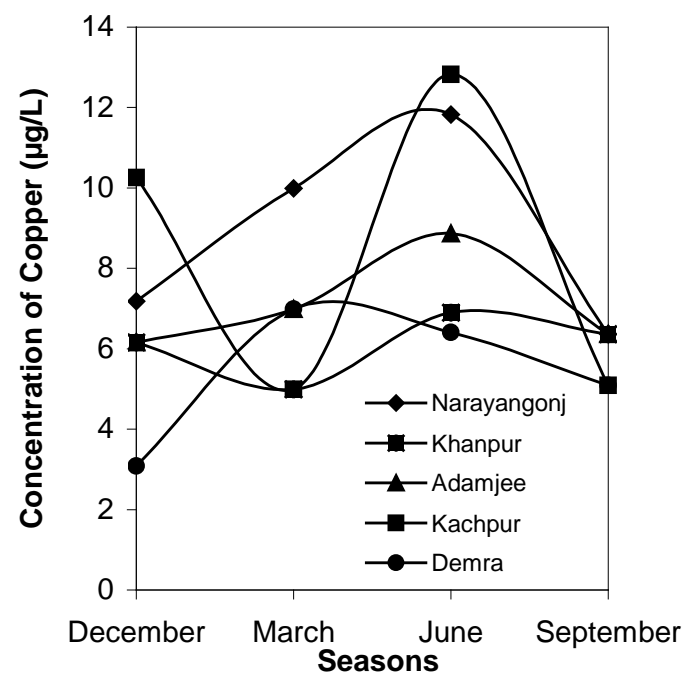

Fig. 5. Seasonal variation of Copper $(\mu \mathrm{g} / \mathrm{l})$ in water samples at different locations of the Sitalakhya river.

\section{CONCLUSION}

This study was carried out to evaluate the contamination and seasonal variation of toxic metals in the water samples of the Sitalakhya river. Trace metal concentrations in surface water of the Sitalakhya river were measured for one year (Dec.'04 to Sept.'05) at five sites, Narayanganj, Khanpur, Adamjee, Kanchpur, Demra. The concentration of iron was found maximum among all of the trace elements at Khanpur location which was much higher than the standard permissible limit. The manganese concentration was also much higher than the standard level. The heavy metal concentration vary according to the nature of the sites and the intensity of the industrial and agricultural run off. The result may differ from site to site, depending on the actual natural and anthropogenic conditions. On the other hand the knowledge on the results of this interaction is an essential requirement for management of the natural water resources and for environmental protection ${ }^{(9)}$. From the study of the surface water quality of the Sitalakhya river, it can be said that the water of the river is not an immediate threat to ecosystem though the concentration of some parameters is alarming. But the condition of the river side urbanization and industrialization may cause all kind of water pollution in the near future.

\section{REFERENCES}

1. Ahmed AKsoy, Dilek Demirezen and Fatih Duman, “.Bioaccumulation, detection and analyses of heavy metal pollution in sultan marsh and its environment”, Water, Air and soil pollution, 164: p. 241, 2005. 
2. M. Pettine And M. Camusso, "Soluble and Particulate metals in the Po river, Italy, Factors affecting Concentrations and Partitioning," The science of the total Environment, 145, 243, 8, 1994.

3. L ZhANG, AND Z. KeZHun, "Background values of Trace elements in the Source area of the Yangtze River," The science of the total Environment, 125. pp. 391, 1992.

4. C. E. Boyd and W. W. Walley, "Total Alkalinity and Hardness of Surface Waters in Alabama and Mississippi”. Alabama Agricultural Experiment Station Bulletin no. 465. Birmingham, Ala.: Auburn University Press. 1975.

5. T. Jaleel, M. Asraf, M. Jaffar and M. Afzal, "Population status of the Indus River, Pakistan, through Heavy metal and Micro nutrient content offish, sediment and water.” Water Research, 30, (6) 1337-1344, 1996.

6 B. M. Jeniffer, AND J. N. Lester, “Anthropogenic Heavy Metal Inputs to Lowland River Systems, A Case Study, the River Stou, U.K.” Water, Air \& Soil pollution, 78, 279. 1994.

7. O. N. Jerome, “Chemistry of the River Niger,” The Science of the total Environment, 58. 81, 1986.

8. A.C. Paul, M. Parameswarn and K.C. Pillas, "Trace metals and Lanthanide in a Tropical River Environment” Water, Air and Soil Pollution, 74, 142-153, 1994.

9. Xudong Xie, Stefan Norea, Zsolt Berner and Doris Stuben, “A GiS supported multivariate statistical analysis of relationship among stream water chemistry geology and lead use in Baden Wurttemberg, Germany”, Water, Air and Soil Pollution 167, 39, 2005.

Journal of Bangladesh Academy of Sciences, Vol. 32, No. 1, 13-22, 2008 